\title{
Influences of the Welding Heat Input and the Repeated Repair Welding on Ti-3Al-2.5V Titanium Alloy
}

\author{
Hui-Jun Yi $\cdot$ Yong-Jun Lee $\cdot$ Kwang-O Lee
}

Received: 15 August 2014/Revised: 27 December 2014/Published online: 5 March 2015

(C) The Chinese Society for Metals and Springer-Verlag Berlin Heidelberg 2015

\begin{abstract}
The primary purpose of this study was to determine the effects of gas tungsten arc welding heat input on the high-temperature tensile properties, toughness, and microstructural features of titanium alloy Ti-3Al-2.5V. The secondary objective was to examine the effect of the repeated repair welding on the properties of the alloy. It was also found that the mechanical properties progressively decreased with increasing the repair welding cycles, especially in the case of the weldment after the first welding repair. It was observed that the sizes of the acicular $\alpha^{\prime}$ and prior $\beta$ grain boundaries as well as the volume fraction of the acicular $\alpha^{\prime}$ phases increased with increasing the welding heat input. In addition, the amount and size of the acicular $\alpha^{\prime}$ phases were found to increase with increasing the repair welding cycles.
\end{abstract}

KEY WORDS: Ti-3Al-2.5V; Repair welding; Heat input; Tensile properties; Microstructure

\section{Introduction}

Owing to the high strength-to-weight ratio, exceptional corrosion resistance, and good fatigue resistance of titanium, its alloys are widely used in gas turbine engines, aircraft frames, seawater coolers, and desalination and other chemical plants [1]. The joining of titanium alloy parts is usually done by welding, especially gas tungsten arc welding (GTAW) process. This is because of the ability of the process to produce high-quality welds, its mechanization, and the extensive industrial experience available. Furthermore, the relatively low conductivity and coefficient of thermal expansion of titanium minimize the possibility of distortion by welding. However, the welding of titanium alloys is difficult owing to the extremely high

Available online at http://link.springer.com/journal/40195

H.-J. Yi $(\bowtie) \cdot$ Y.-J. Lee · K.-O. Lee

School of Mechanical Engineering, Pusan National University, Busan 609-735, Korea

e-mail: yi.h.jun@gmail.com chemical reactivity of titanium at high temperatures. During the welding of the titanium alloy, the material easily absorbs oxygen and nitrogen from the atmosphere. Although the absorption of limited amounts of oxygen and nitrogen by the solid material significantly increases its strength, excessive amounts result in brittleness [2]. Thus, the weldability of titanium alloys is usually assessed based on the toughness and ductility of the weld metal (WM) and the heat-affected zone (HAZ) [3-5]. The HAZ of $\alpha-\beta$ titanium alloys such as Ti-3Al-2.5V and Ti-5Al-2.5Sn tends to become brittle when heat-treated to high strength levels, and the fusion zone (FZ) is known to exhibit poor ductility relative to the base material. The mechanical properties of the welded zone are altered by the chemical reactions of the WM with the filler metal, resulting in the influx of impurities, dynamic solidification, and large inclinations [6,7]. Depending on the characteristics of the base metal (BM), unexpected changes may also occur. Furthermore, a change in the chemical composition or structure of the BM may reduce the strength or ductility of the BM. Particularly, growth of the grains of the material may be induced by the welding heat. The grains in the HAZ may become coarse, depending on the cooling 
Table 1 Chemical compositions of base metal and filler metal (wt\%)

\begin{tabular}{lllllllll}
\hline Identification & $\mathrm{C}$ & $\mathrm{Fe}$ & $\mathrm{Al}$ & $\mathrm{V}$ & $\mathrm{N}$ & $\mathrm{O}$ & $\mathrm{H}$ & $\mathrm{Ti}$ \\
\hline Base metal & 0.019 & 0.074 & 3.07 & 2.43 & 0.015 & 0.10 & 0.005 & Bal. \\
Filler metal & 0.02 & 0.01 & 2.98 & 2.48 & 0.01 & 0.10 & 0.001 & Bal. \\
\hline
\end{tabular}

conditions; therefore, the microstructure may be altered [8-10].

The primary objective of the present study was to evaluate the effect of the heat input on the high-temperature tensile properties, impact toughness, and microstructure of $\mathrm{Ti}-3 \mathrm{Al}-2.5 \mathrm{~V}$ weldment. In titanium welding, weld porosity originates at the trailing edge of the weld pool, and recent studies have identified a qualitative dependence of the weld porosity on the surface conditions. Titanium oxide forms on the surface of titanium alloys if sufficient level of oxygen is present in the surrounding media. This self-healing oxide layer gives titanium its excellent corrosion resistance in different types of aggressive corrosion media. However, the oxide layer is hygroscopic and therefore absorbs moisture from the atmosphere under ambient conditions. The removal of the hydrated layer prior to welding is therefore critical to minimize the potential hydrogen content of the melt pool. Consequently, the mechanical cleaning or chemical pickling used to remove the hydrated layer and other surface contaminations significantly affects the occurrence of weld porosity [1113]. The avoidance of porosity requires that the molten weld pool should be shielded from oxygen or hydrogen during welding [14-16]. This means that the joint should be thoroughly degreased prior to welding, and adequate inert gas shielding at low dew point should be applied. However, it is not easy to prevent weld porosity during the welding of titanium alloy, and once porosity is detected by nondestructive test (NDT) after welding, repair welding should be undertaken. Although repair welding has been applied for some years in industry, the properties of the repair weldment are yet to be investigated. Many studies conducted on the effect of repair welding focused on investigating the effect of the residual stress by finite element analysis [17-19]. Hence, the secondary objective of this study was to determine the effects of repeated repair welding on the microstructure and the tensile properties of Ti-3Al-2.5V alloy.

\section{Experimental}

\subsection{Experiments on Effect of Welding Heat Input}

Welding experiments used in various heat input conditions were performed on 2.0-mm-thick plates of titanium alloy Ti-3Al-2.5V. The chemical compositions of the base metal and filler metal are given in Table 1. The GTAW process using $99.9 \%$ purity argon gas was employed, together with shielding and gas purging to prevent oxidation during the welding. An automatic welding machine fully equipped with an out-of-chamber purging device was used for the experiments (see Fig. 1). Table 2 gives the parameters of the welding experiments.

\subsection{Experiments on Effect of Repeated Welding}

Repeated repair welding experiments were performed on 2.0-mm-thick plates of titanium alloy $\mathrm{Ti}-3 \mathrm{Al}-2.5 \mathrm{~V}$. The GTAW process using $99.9 \%$ argon gas was used for the welding and repeated repair welding. An automatic welding machine fully equipped with an out-of-chamber purging device was employed to prevent oxidation during the welding. Table 3 gives the parameters of the welding and repair welding.

The adopted procedure of the welding and repeated repair welding is as follows:

(1) The original welding was done by GTAW using a $2.0 \mathrm{~mm}$ butt-weld joint.

(2) The reinforcement and back bead of the original weld seam were removed by machining, and the first repair welding was then done, and the first repair weldment obtained.

(3) The reinforcement and back bead of the first repair welding seam were removed, and the second repair

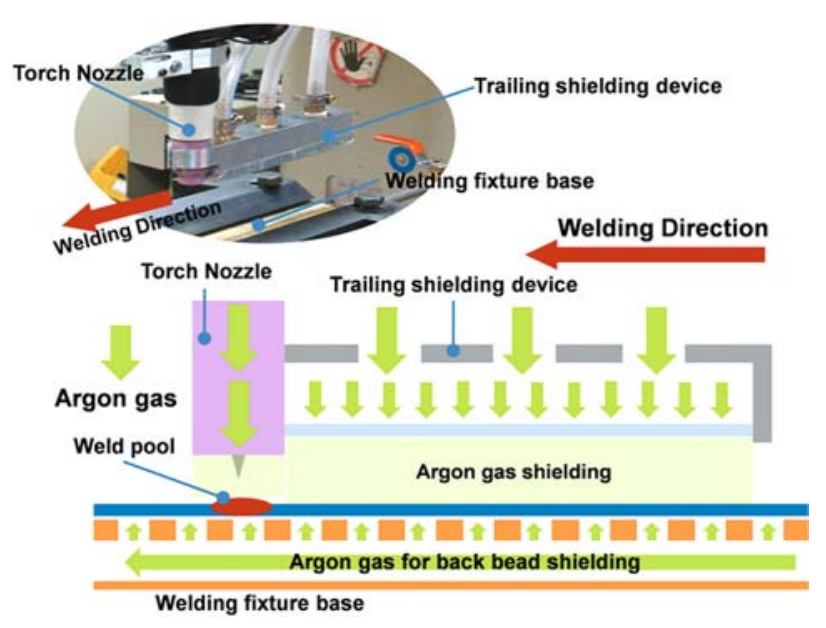

Fig. 1 Illustration of the welding device 
Table 2 Welding and repair welding parameters

\begin{tabular}{llllc}
\hline Identification & $\begin{array}{l}\text { Ampere } \\
(\mathrm{A})\end{array}$ & $\begin{array}{l}\text { Voltage } \\
(\mathrm{V})\end{array}$ & $\begin{array}{l}\text { Welding speed } \\
(\mathrm{CPM})\end{array}$ & $\begin{array}{l}\text { Heat input } \\
(\mathrm{kJ} / \mathrm{cm})\end{array}$ \\
\hline H01 & 135.0 & 13.6 & 20 & 8.8 \\
H02 & 145.0 & 14.0 & 20 & 9.8 \\
H03 & 155.0 & 14.1 & 20 & 10.6 \\
H04 & 165.0 & 14.4 & 20 & 11.4 \\
H05 & 175.0 & 14.7 & 20 & 12.4 \\
\hline
\end{tabular}

Table 3 Welding and repair welding parameters

\begin{tabular}{lllll}
\hline Identification & & $\begin{array}{l}\text { Ampere } \\
\text { (A) }\end{array}$ & $\begin{array}{l}\text { Voltage } \\
\text { (V) }\end{array}$ & $\begin{array}{l}\text { Welding speed } \\
\text { (CPM) }\end{array}$ \\
\hline Original welding & R0 & 150.0 & 15.0 & 20 \\
1st repair welding & R1 & 150.0 & 15.0 & 20 \\
2nd repair welding & R2 & 150.0 & 15.0 & 20 \\
3rd repair welding & R3 & 150.0 & 15.0 & 20 \\
4th repair welding & R4 & 150.0 & 15.0 & 20 \\
5th repair welding & R5 & 150.0 & 15.0 & 20 \\
\hline
\end{tabular}

welding was done, and the second repair weldment obtained.

(4) The reinforcement of the welding seam was once again removed, and additional welding was done on the residue of the previous weldment. This process was repeated until the fifth repair welding was accomplished.

\subsection{Mechanical and Microstructural Test}

The tensile test, the notch tensile test, hardness test, and Charpy V-notch tests were used to determine the effect of the heat input, whereas the tensile test and the notch tensile test were used to determine the effect of repeated repair welding.

The tensile and the notch tensile test specimens were prepared in accordance with ASTM E8 M-05 guidelines. The tests were conducted using a $100 \mathrm{kN}$ Universal Testing Machine (Instron 8501). The specimens were loaded at a rate of $1.5 \mathrm{kN} / \mathrm{min}$ in accordance with ASTM specifications. The tensile tests were conducted at temperatures of 25,300 , and $500{ }^{\circ} \mathrm{C}$. The hardness of the specimens was measured by the macro-Vickers hardness test in accordance with ASTM E92-82(2003) by applying a load of $49 \mathrm{~N}$ over a period of $10 \mathrm{~s}$. The measurements were taken $2 \mathrm{~mm}$ from the top of the WM. A Charpy V-notch impact test was used to examine the toughness properties of the weldment. The V-notch was created at the position of $1 \mathrm{~mm}$ from the fusion line (FL $+1.0 \mathrm{~mm}$ ) of the WM. All the specimens and tests were prepared and conducted in accordance with ASTM A370. The microstructure of each specimen was examined by the optical and scanning electron microscopes.

\section{Results}

\subsection{Mechanical Properties Under Various Heat Input Conditions}

Figure 2 shows the effect of the heat input on the tensile strength at $25^{\circ} \mathrm{C}$. Figures 3 and 4 show the properties at 300 and $500{ }^{\circ} \mathrm{C}$, respectively. The highest tensile strength was observed for the $\mathrm{H} 03$ specimen $(9.6 \mathrm{~kJ} / \mathrm{cm}$ heat input). It can also be observed, the tensile strength of the H05 specimen (over $12.0 \mathrm{~kJ} / \mathrm{cm}$ heat input) decreased as the temperature was increased from the ambient temperature. Figure 5 shows the Charpy impact test results for various heat inputs. From Fig. 5, it is revealed that the Charpy impact toughness of the WM increased with increasing heat input. However, the Charpy impact toughness of the HAZ (at the notch location, FL $+1.0 \mathrm{~mm}$ ) did not exhibit the same pattern. As shown in Fig. 6, the notch toughness of the HAZ decreased with increasing heat input. This tendency was also observed in the results of the notch tensile test. The NSR (notch strength ratio) of the HAZ decreased with increasing heat input. Figure 7 shows the hardness distribution of the weldment. No specific differences were observed among the hardness distribution of the WM specimens. However, the hardness distribution in the HAZ increased with increasing heat input.

\subsection{Effect of the Repeated Repair Welding} on the Tensile and Notch Tensile Characteristics

Figure 8 shows the effect of repeated repair welding on the ultimate tensile strength at temperatures of 25,300 , and

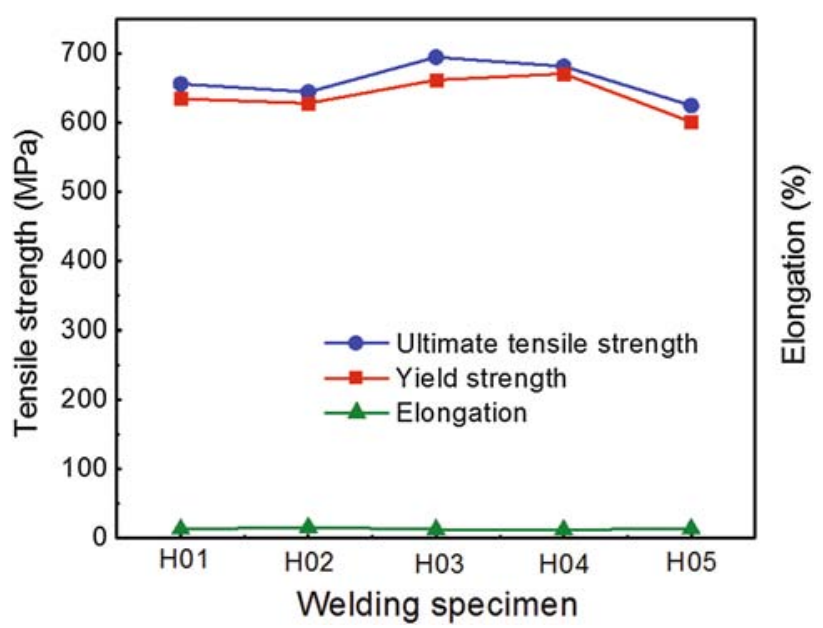

Fig. 2 Effect of welding heat input on ultimate tensile strength at ambient temperature 


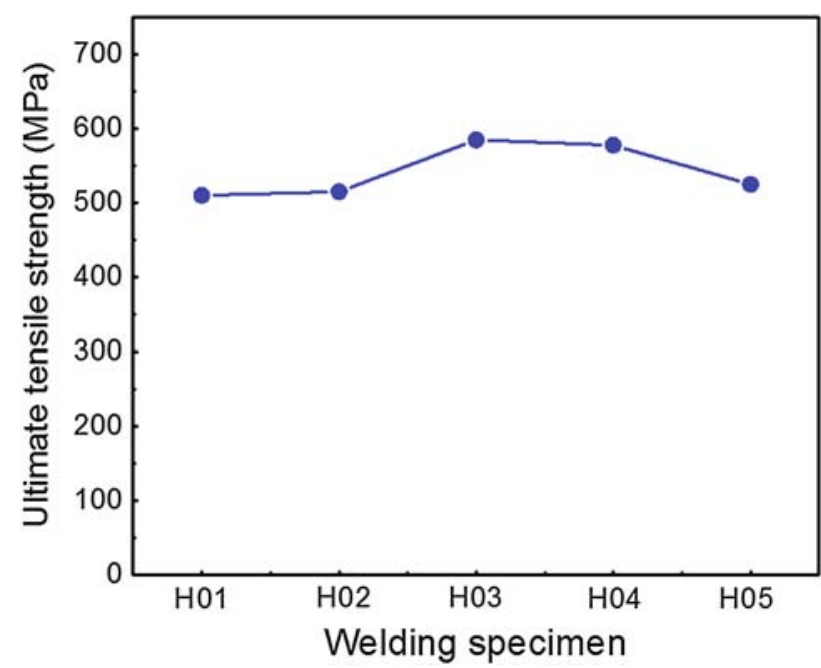

Fig. 3 Effect of welding heat input on ultimate tensile strength at $300{ }^{\circ} \mathrm{C}$ temperature

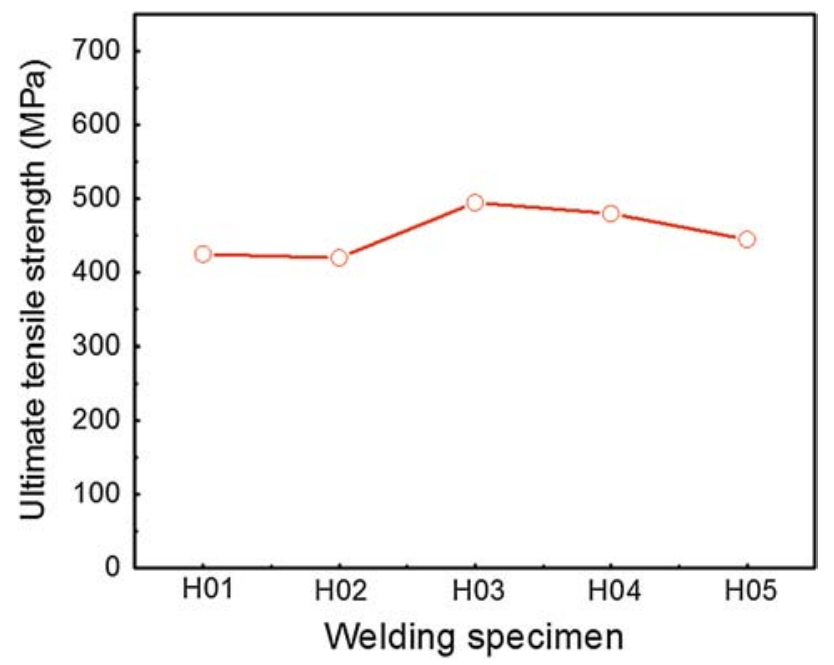

Fig. 4 Effect of welding heat input on ultimate tensile strength at $500{ }^{\circ} \mathrm{C}$ temperature

$500{ }^{\circ} \mathrm{C}$. The following results can be observed from the graph: (1) The R0 specimen has the highest tensile strength, and the R1 specimen the lowest, at temperatures of 25,300 , and $500{ }^{\circ} \mathrm{C}$; (2) the tensile strength tends to increase slightly with increasing cycles of the repeated repair welding from $\mathrm{R} 1$ to $\mathrm{R} 5$ at temperatures of 25,300 , and $500{ }^{\circ} \mathrm{C}$; (3) the tendency of the tensile strength is the same at all temperatures.

Figure 9 shows the effect of the repeated welding on the notch tensile strength at temperatures of 25,300 , and $500{ }^{\circ} \mathrm{C}$. Unlike in the tensile test results, the R5 specimen has the highest notch tensile strength at a temperature of $25^{\circ} \mathrm{C}$. The R0 specimen has the highest notch tensile strength at temperatures of 300 and $500{ }^{\circ} \mathrm{C}$.

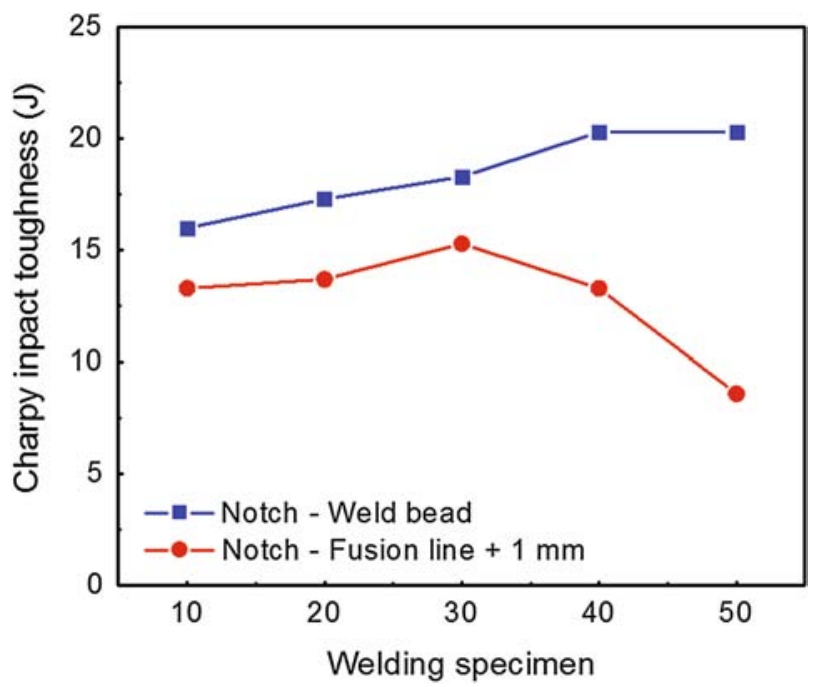

Fig. 5 Charpy impact test results with various welding heat input condition

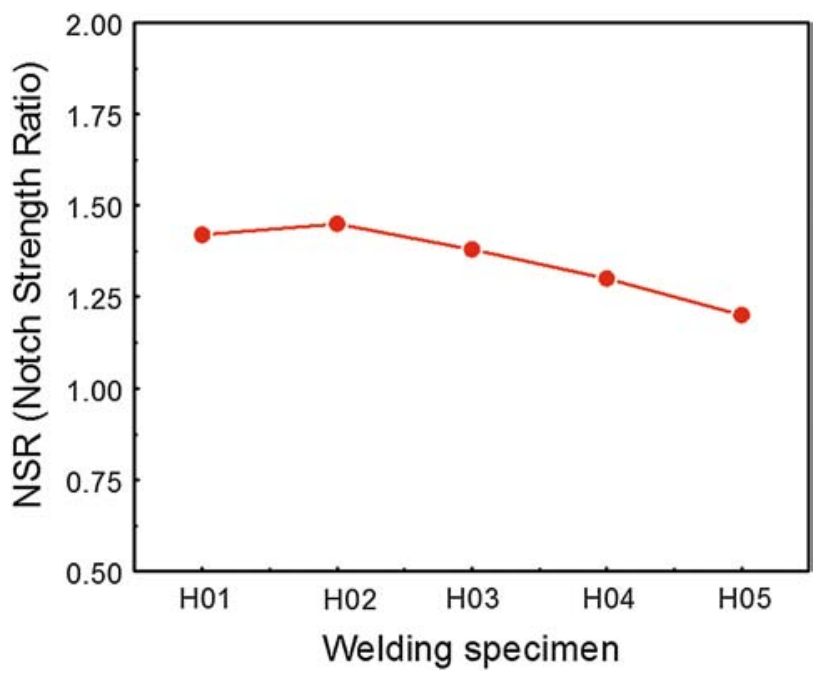

Fig. 6 Notch strength ratio (NSR) results with various welding heat input condition

Figure 10 shows the effect of the repeated welding on the NSR. It can be observed, the values improved for all specimens at all temperatures. The value of NSR is greater than 1.0 at all temperatures for specimens (R0-R5). The R0 specimen has the lowest value of NSR owing to its highest tensile strength at all temperatures.

\subsection{Microstructural Observation}

\subsubsection{Effect of the Welding Heat Input on the Microstructure}

Figures 11 and 12 show the microstructures of the WM and HAZ, respectively. Both have acicular $\alpha^{\prime}$ (martensite) and prior 


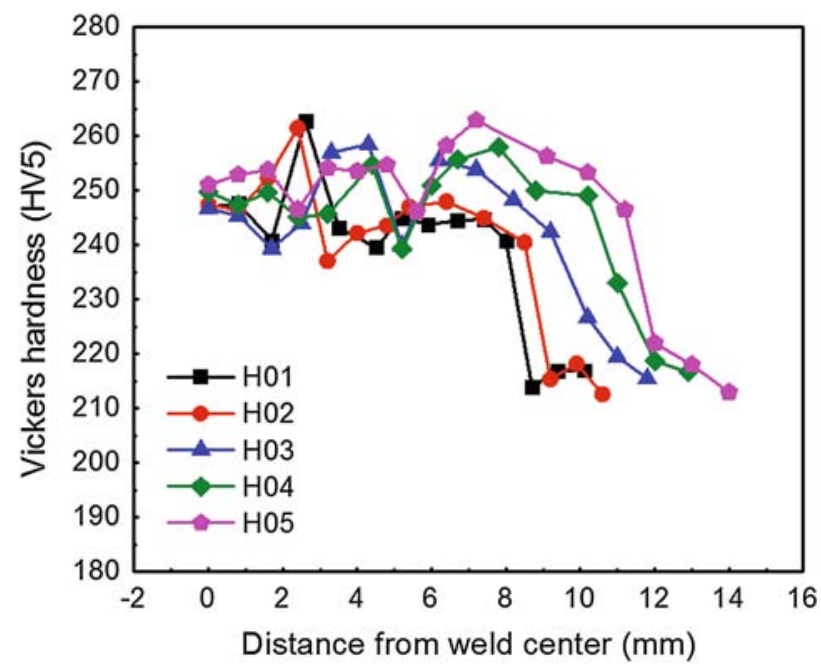

Fig. 7 Hardness distribution as per heat input condition

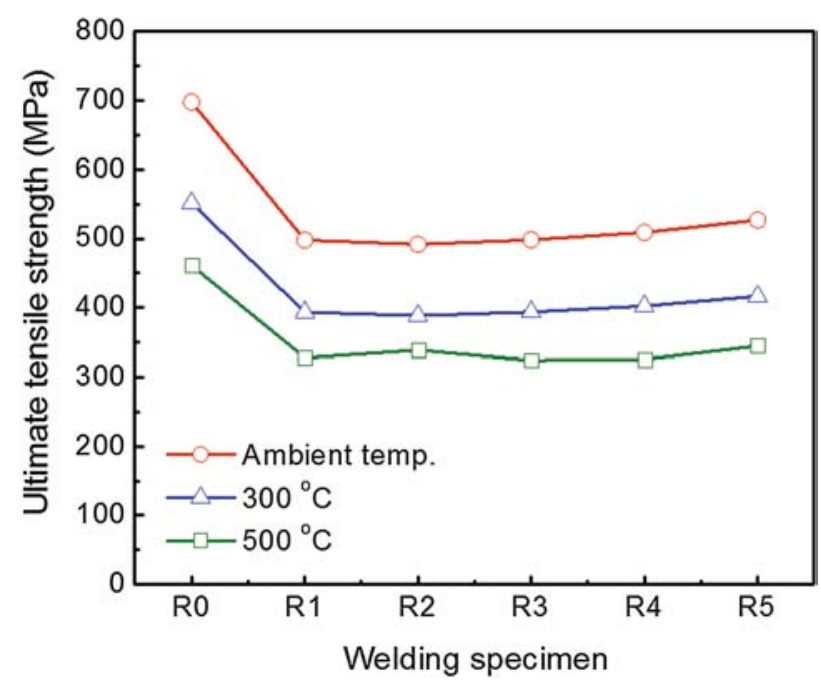

Fig. 8 Effect of repeated repair welding on ultimate tensile strength

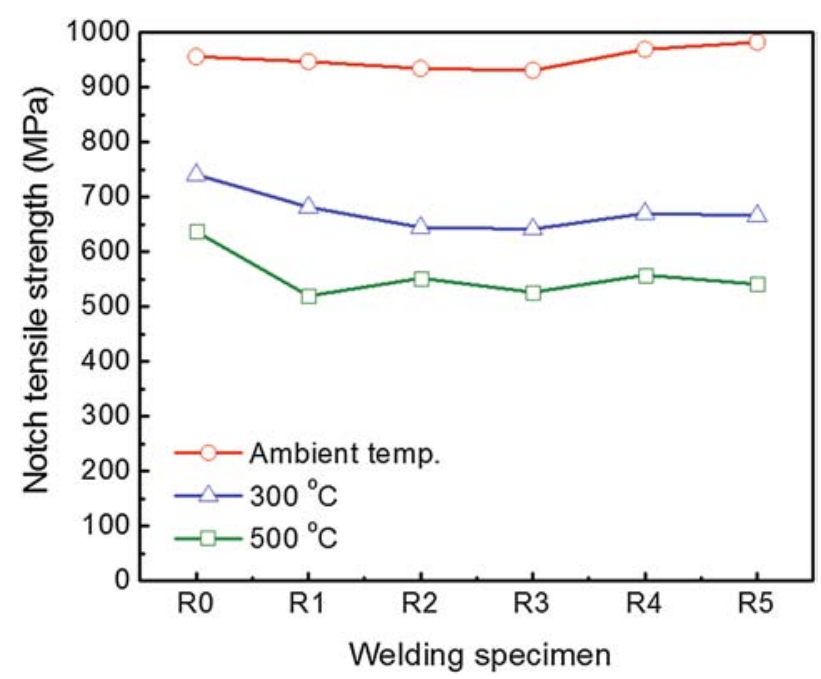

Fig. 9 Effect of repeated repair welding on notch tensile strength

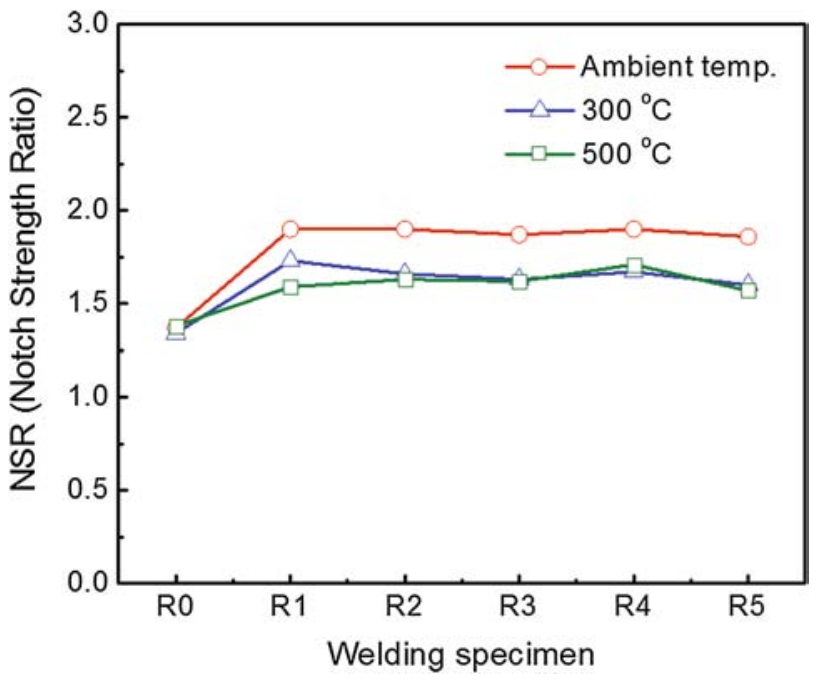

Fig. 10 Effect of repeated repair welding on NSR

$\beta$ grain boundary morphologies. The acicular $\alpha^{\prime}$ was not altered by the welding heat input. However, with increasing heat input, the acicular $\alpha^{\prime}$ and prior $\beta$ grain boundaries become larger in both the WM and HAZ. Furthermore, the volume fraction of the acicular $\alpha^{\prime}$ phase of the HAZ increases with increasing heat input. It is thus assumed that increasing heat input may promote grain growth and martensite transformation.

\subsubsection{Effect of Repeated Repair Welding on Microstructure}

Figure 13 shows the WM microstructures of R0 and R1-R5. The WM of R0 predominantly contains acicular $\alpha^{\prime}$ and prior $\beta$ grain boundary morphologies. The WM microstructures of R1-R5 contain more numerous and larger acicular $\alpha^{\prime}$ and prior $\beta$ grain boundaries compared to those of $\mathrm{R} 0$. In addition, with increasing repair welding cycles, the acicular $\alpha^{\prime}$ phases gradually increase and become thicker and coarser. Figure 14 shows the microstructures of HAZ of R0 and R1-R5. The HAZ also consists of acicular $\alpha^{\prime}$ and prior $\beta$ grain boundary morphologies. The acicular $\alpha^{\prime}$ phases are not altered by the number of welding cycles. However, with increasing the repair welding cycles, the acicular $\alpha^{\prime}$ and prior $\beta$ grain boundaries increase in size and number. Moreover, no significant phase differences can be observed among the structures of R0-R5. It is thus assumed that the welding heat does not melt the HAZ, and that increasing repair welding cycles promotes grain growth and $\beta$-to- $\alpha^{\prime}$ transformation. These tendencies can also be observed by the SEM in Fig. 13.

\section{Discussion}

The tensile strength, notch toughness, ductility, and hardness of welded $\mathrm{Ti}-3 \mathrm{Al}-2.5 \mathrm{~V}$ at ambient and high temperatures 

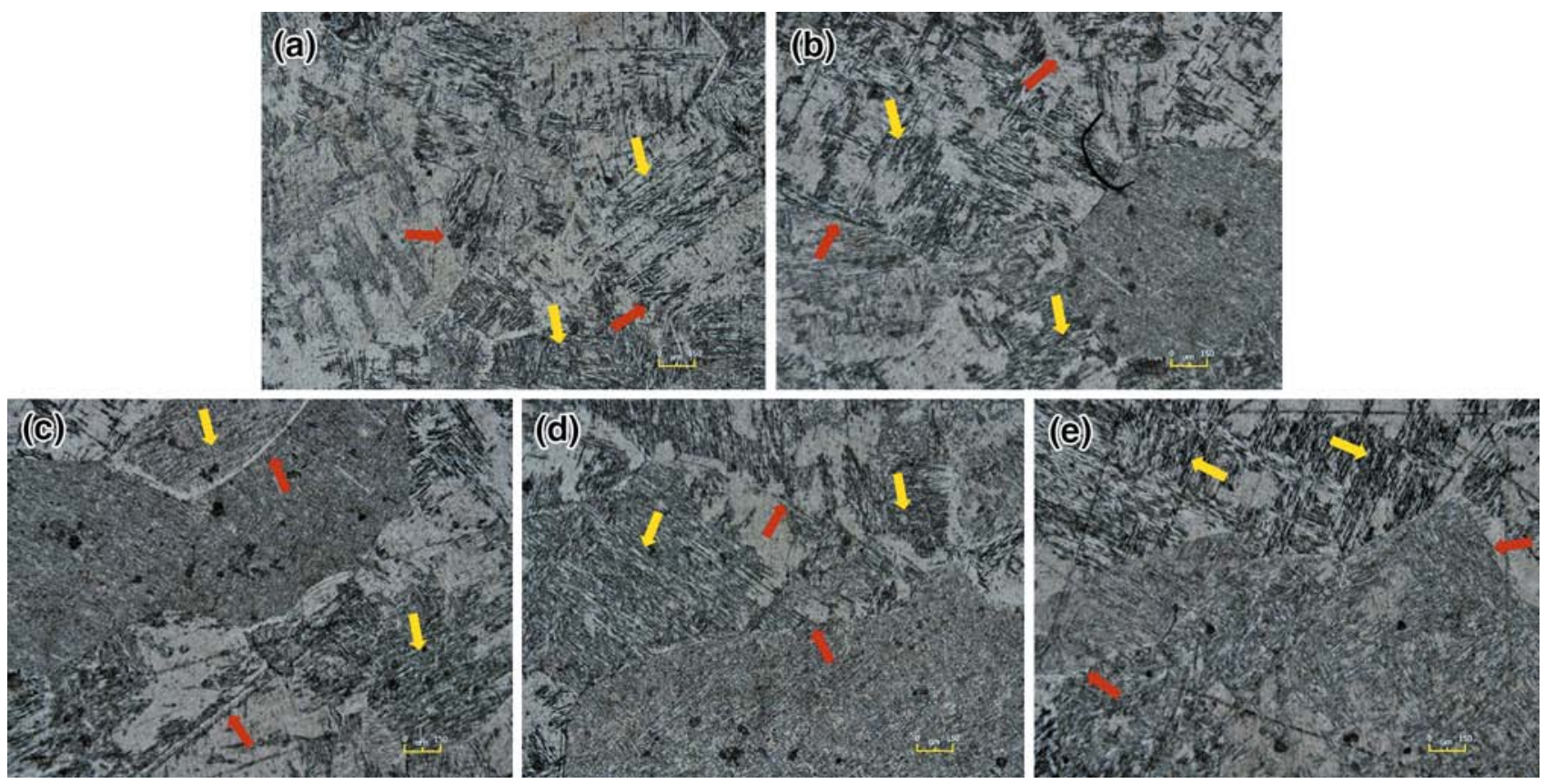

Fig. 11 Microstructures of weld metal on various welding heat input energy: a weld metal, H01; b weld metal, H02; c weld metal, H03; d weld metal, H04; e weld metal, H05. The yellow arrows indicate acicular $\alpha^{\prime}$ precipitate in $\beta$ grains and the red arrows indicate prior $\beta$ grain boundaries

are related to the microstructures of the material. The mechanical and toughness properties of both the WM and HAZ are determined by their microstructures. During welding, solidification occurs in the primary $\beta$ phase, and the increased cooling rate is accompanied by an increase in the $\alpha^{\prime}$ phase due to solidification of the liquid metal ( $\beta$ phase) and increased $\beta$-to- $\alpha^{\prime}$ solid-state transformation. This process is induced by the welding heat input. The grain size is a function of the heat input, the heat generated during welding stimulating grain growth. With increasing the welding heat input, the grains of the WM and HAZ become coarser, and the volume fraction of martensite increases in the HAZ. It is considered that welding heat input promotes the grain growth in the WM and surrounding area. Grain growth and
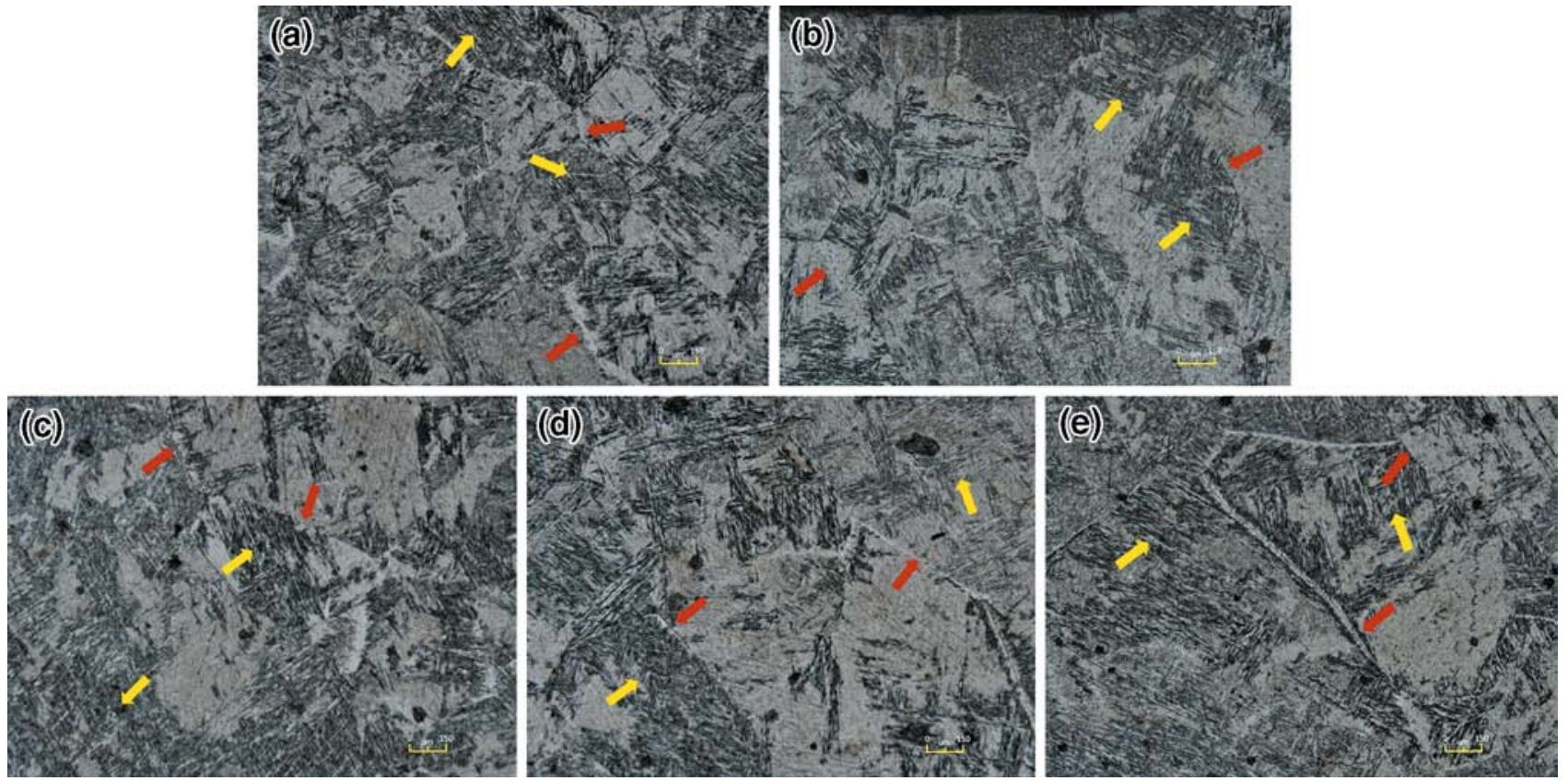

Fig. 12 Microstructures of heat-affected zone on various welding heat input energy: a HAZ, H01; b HAZ, H02; c HAZ, H03; d HAZ, H04; e HAZ, H05. The yellow arrows indicate acicular $\alpha^{\prime}$ precipitate in $\beta$ grains and the red arrows indicate prior $\beta$ grain boundaries 

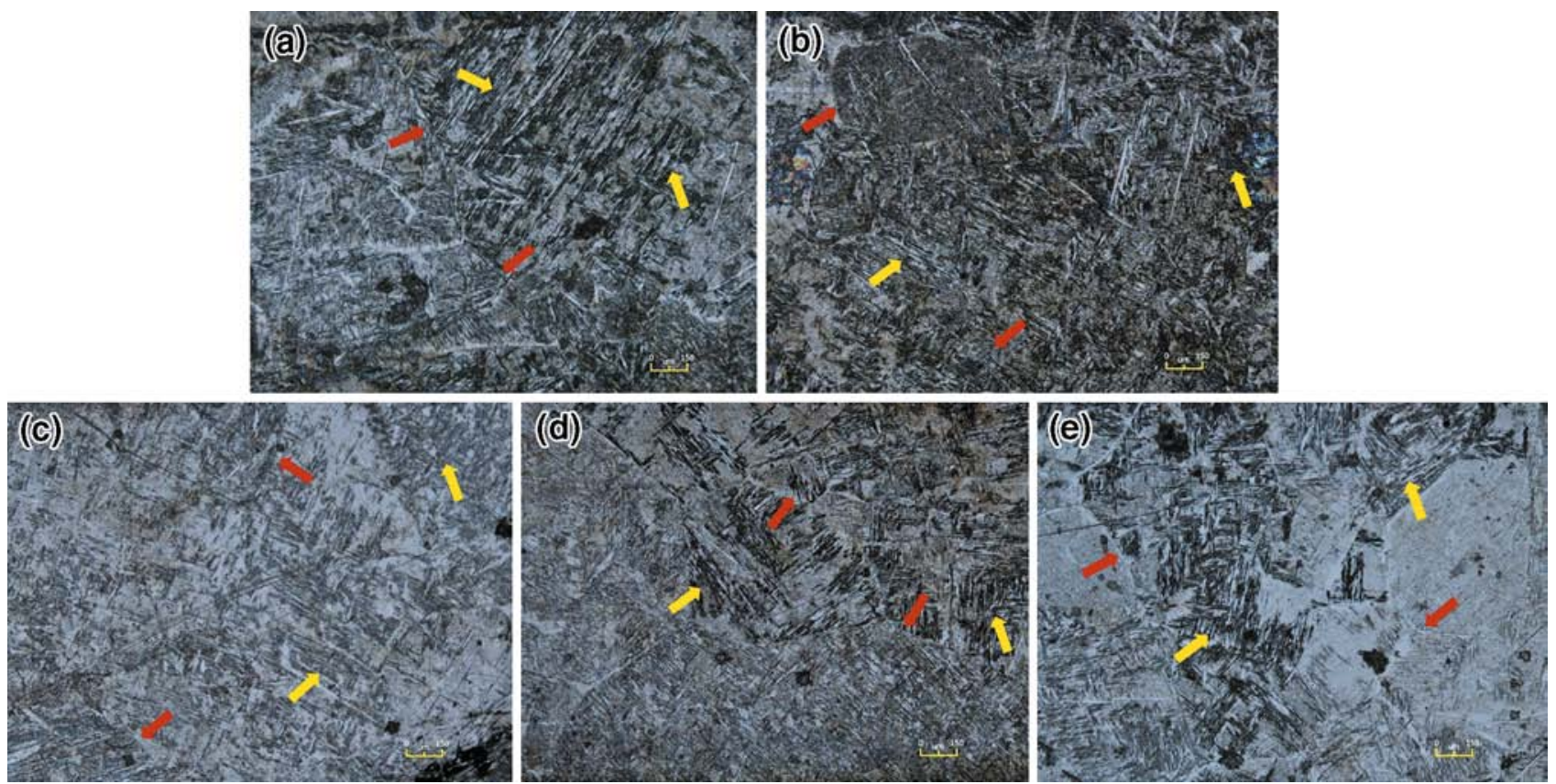

Fig. 13 Weld metal microstructures of repeated repair welding: a 1st repair weld metal (R1), b 2nd repair weld metal (R2), c 3rd repair weld metal (R3), d 4th repair weld metal (R4), e 5th repair weld metal (R5). The yellow arrows indicate acicular $\alpha^{\prime}$ precipitate in $\beta$ grains and the red arrows indicate prior $\beta$ grain boundaries
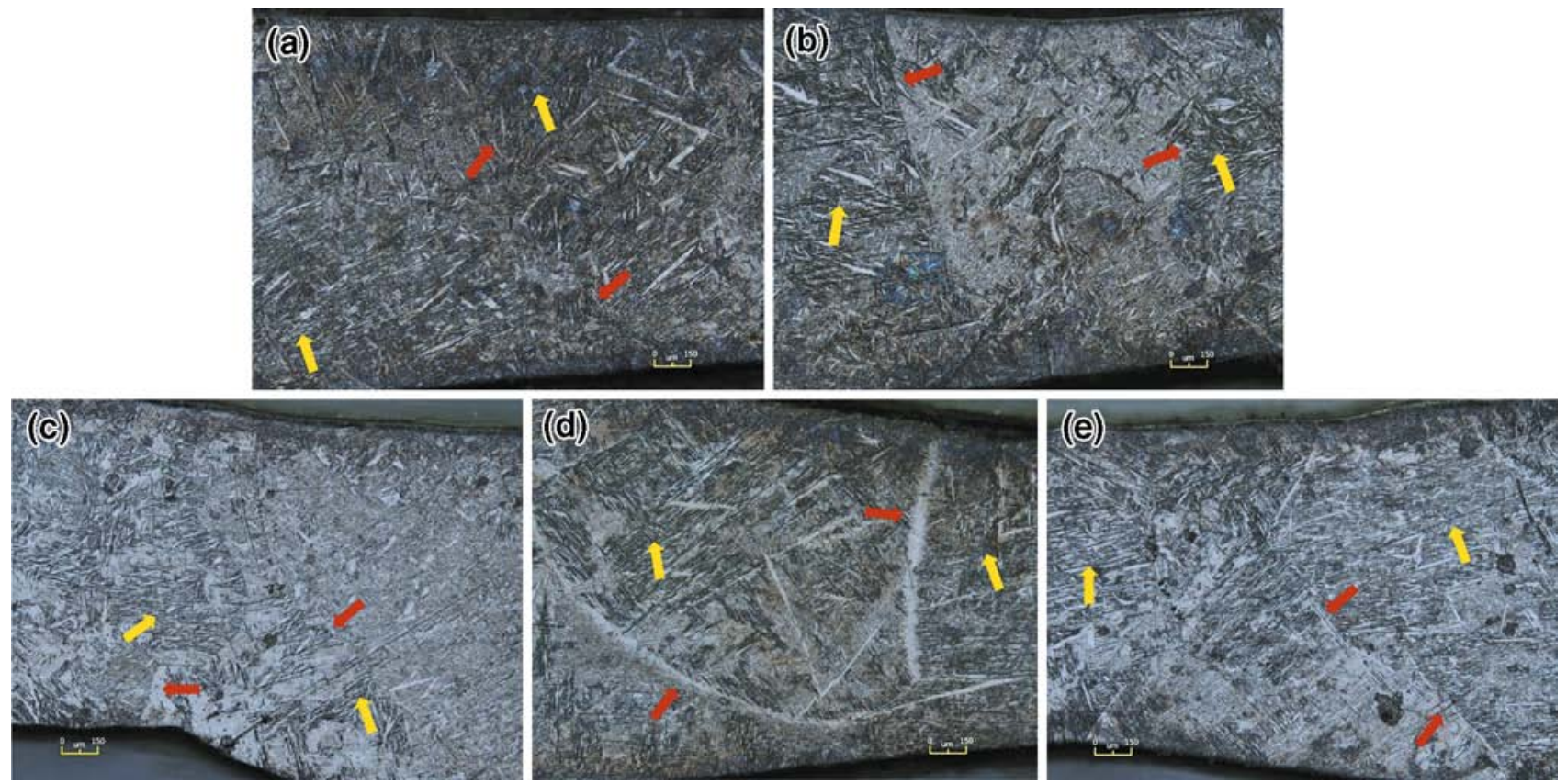

Fig. 14 HAZ microstructures of repeated repair welding: a 1st repair H.A.Z (R1), b 2nd repair H.A.Z (R2), c 3rd repair H.A.Z (R3), d 4th repair H.A.Z (R4), e 5th repair H.A.Z (R5). The yellow arrows indicate acicular $\alpha^{\prime}$ precipitate in $\beta$ grains and the red arrows indicate prior $\beta$ grain boundaries

relatively fast cooling in the HAZ in turn promote martensite transformation. The grain size and cooling conditions are important for determining the proportions of the various transformation products. It can thus be said that the mechanical properties of the WM vary with the welding heat input (Fig. 15).
Multiple repair welding significantly affects the mechanical properties of $\mathrm{Ti}-3 \mathrm{Al}-2.5 \mathrm{~V}$, especially the tensile properties. Increasing the repair welding cycles may promote $\beta$-to- $\alpha^{\prime}$ transformation and affects the grain size. After the first repair welding, subsequent repairs progressively promote the grain growth in the HAZ. In the present 


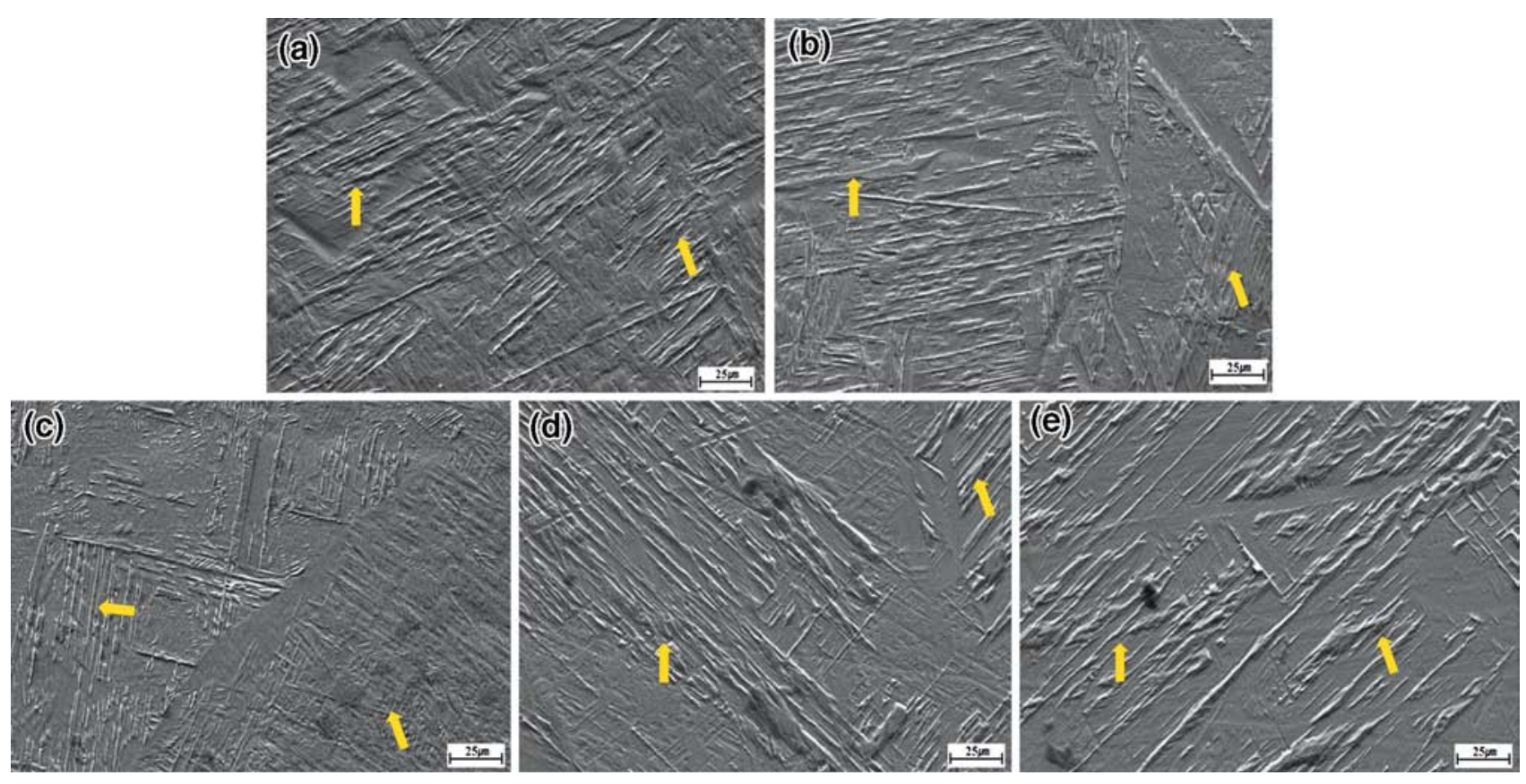

Fig. 15 SEM images of HAZ microstructures of repeated repair welding: a 1st H.A.Z (R1), b 2nd H.A.Z, c 3rd H.A.Z, d 4th H.A.Z, e 5th H.A.Z. The yellow arrows indicate acicular $\alpha^{\prime}$

study, the decreasing strength was observed for the specimens R1-R5 due to the generation of new grains, morphology change, and the grain growth. The welding heat stimulated grain formation and increase in grain size. With repeating welding repair, more heat was inputted to the repaired area, thereby stimulating growth of the structures in the WM and surrounding areas.

\section{Conclusions}

(1) The Charpy impact toughness of the WM and HAZ increased with increasing welding heat input. The tensile strength at ambient and high temperatures decreased for all specimens from H05 (more than $12.0 \mathrm{~kJ} / \mathrm{cm}$ heat input) to the $\mathrm{H} 01$ specimen.

(2) The original weldment had the highest tensile strength, and the tensile strength decreased with increasing repair welding cycles at all temperatures.

(3) The tendencies of the ductility of the WM and HAZ were the same, regardless of the welding heat input and number of repair welding cycles.

(4) With increasing heat input, the sizes of the acicular $\alpha^{\prime}$ and prior $\beta$ grain boundaries increased, and the volume fraction of the acicular $\alpha^{\prime}$ phases in the heataffected zone is also increased.

(5) The number of acicular $\alpha^{\prime}$ phases increased with increasing repair welding cycles.

\section{References}

[1] G. Lutjering, J.C. Williams, Titanium (Springer, New York, 2003)

[2] D.J. Allen, J. Weld Met. Fabric. 63, 225 (1995)

[3] I. AghaAli, M. Farzam, M.A. Golozar, I. Danaee, Mater. Des. 54, 331 (2014)

[4] L.M. Liu, X. Du, M.L. Zhu, G.Q. Chen, Mater. Sci. Eng. A 445, 691 (2007)

[5] M. Balasubramanian, V. Jayabalan, V. Balasubramanian, Int. J. Manuf. Technol. 39, 474 (2008)

[6] M. Balasubramanian, V. Jayabalan, V. Balasubramanian, Mater. Des. 29, 1359 (2008)

[7] M. Balasubramanian, V. Jayabalan, V. Balasubramanian, Mater. Des. 29, 1459 (2008)

[8] M. Balasubramanian, V. Jayabalan, V. Balasubramanian, Mater. Lett. 62, 1102 (2008)

[9] S. Sundaresan, G.D.J. Ram, G.M. Reddy, Mater. Sci. Eng. A 262, 88 (1999)

[10] T. Mohands, D. Banerjee, V.V.K. Rao, Mater. Sci. Eng. A 254, 147 (1998)

[11] M.J. Donachie, Titanium and titanium alloys (ASM international, Ohio, 1982)

[12] R.R. Boyer, Mater. Sci. Eng. A 213, 103 (1996)

[13] L.S. Smith, M.F. Gittos, TWI Research Report 658/1998. TWI, 1998

[14] A.K. Bhaduri, S.K. Rai, T.P.S. Gill, Sci. Technol. Weld. Join. 6, 89 (2001)

[15] A.R. Alian, M. Shazly, M.M. Megahed, Appl. Mech. Mater. 313, 1660 (2013)

[16] S. Lathabai, B.L. Jarvis, K.J. Barton, Mater. Sci. Eng. A 299, 81 (2001)

[17] T.C. Yang, J.C. Lin, C. Chen, Sci. Technol. Weld. Join. 9, 89 (2004)

[18] W.C. Jiang, B.Y. Wang, J.M. Gong, Mater. Des. 32, 2851 (2011)

[19] W. Zjou, K.G. Chew, Mater. Sci. Eng. A 347, 180 (2003) 